\title{
Percutaneous hepatic radiofrequency for hepatocellular carcinoma: results and outcome of 46 patients
}

This article was published in the following Dove Press journal:

Hepatic Medicine: Evidence and Research

19 May 2015

Number of times this article has been viewed

\author{
Julie Bertrand' \\ Fabrice Caillol' \\ Patrick Borentain ${ }^{2}$ \\ Jean-Luc Raoul' \\ Laurent Heyries ${ }^{2}$ \\ Erwan Bories' \\ Christian Pesenti' \\ Jean-Philippe Ratone ${ }^{2}$ \\ Jean-Paul Bernard ${ }^{2}$ \\ René Gerolami² \\ Marc Giovannini' \\ 'Endoscopy Unit, Paoli Calmettes \\ Institute, Marseille, France; \\ ${ }^{2}$ Department of Hepato- \\ Gastroenterology, Conception \\ Hospital, Marseille, France
}

\begin{abstract}
Radiofrequency ablation (RFA) is a curative option for hepatocellular carcinoma (HCC), the most common primary malignancy of the liver. This bicentric retrospective study includes 46 patients admitted for their first percutaneous RFA for HCC. Sixty-three nodules were treated, with an average size of $32.5 \mathrm{~mm}$. Our study confirms the efficiency of this technique for attaining necrosis of HCC nodules, with few complications. Subgroup studies according to RFA mode (mono- or multipolar), etiology of cirrhosis (alcoholic or viral), and HCC size showed better efficiency for multipolar RFA when applied to small tumors and better survival when the cirrhosis was due to viral infection. However, we noted a high rate of local recurrence in our and other recent works compared to previous studies, probably due to improved imaging techniques. The main problem is still de novo intrahepatic recurrence in diseased livers.
\end{abstract}

Keywords: radiofrequency ablation, cirrhosis, $\mathrm{HCC}$

\section{Introduction}

Hepatocellular carcinoma (HCC) is the most common primary malignancy of the liver, with steadily increasing incidence worldwide; it is the sixth most prevalent of all cancers and the third most common for cancer mortality. ${ }^{1}$ It is also the leading cause of death in cirrhotic patients. There are only three curative options: surgical resection, percutaneous destruction, and liver transplantation (when the Milan criteria are met and the patient is $<65$ years old). Furthermore, this cancer is usually associated with liver cirrhosis or chronic hepatitis so most patients with $\mathrm{HCC}$ are not candidates for surgical resection because of poor hepatic reserve. In this perspective, several minimally invasive techniques were studied such as radiofrequency ablation (RFA), ethanol or acetic acid injections, microwaves, laser, and cryotherapy. ${ }^{2}$ Over time, RFA has gradually replaced ethanol injection, which was the most widely used percutaneous treatment. The aim of this study is to evaluate the practice of RFA at two centers in Marseille, and in particular compare the results according to the mode of RFA (monopolar/multipolar) and the etiology of the cirrhosis.

\section{Materials and methods Patients' characteristics}

This retrospective study includes 46 consecutive patients who underwent RFA for HCC between January 2009 and May 2011 at two institutions in Marseille. There were 41 men and five women, with a mean age of 69.5 years (range 52-84 years). The median follow-up was 14 months (range 6 weeks-36 months), and concerned 44 patients (one patient died 48 hours after the first RFA session and another was not
Correspondence: Fabrice Caillol Endoscopy Unit, Paoli-Calmettes Institute, 232 bd Ste Marguerite, Marseille 13009, France Email fcaillol@free.fr 
re-assessed because of a degradation in his general state of health). Forty patients were cirrhotic; their etiology was alcoholic in 17 cases and viral in 15 cases (mostly hepatitis C). Four patients had both etiologies. Three patients presented hemochromatosis and one dysmetabolic hepatosiderosis. The six remaining patients presented an HCC on a healthy liver. Portal hypertension affected 23 of our cirrhotic patients, in the form of gastric and/or esophageal varices and/or portosystemic shunt observed on computed tomography (CT) scan; however, none of them presented ascites. Regarding hemostasis parameters, 13 patients had a prothrombin time $<70 \%$ (47\% for the lowest) and all the patients except one had a platelet count $>50,000 / \mathrm{mm}^{3}\left(46,000 / \mathrm{mm}^{3}\right.$ for this patient). Thirty-one patients were Child-Pugh stage A, with the highest score being B9. Globally, 63 HCC nodules were managed, with a mean diameter of $32.5 \mathrm{~mm}$ (range $8-60 \mathrm{~mm}$ ). There was a single nodule $<6 \mathrm{~cm}$ in 32 patients, two nodules $<6 \mathrm{~cm}$ in eleven patients, and three nodules $<4 \mathrm{~cm}$ in the three remaining patients. The exclusion criteria were an antecedent of radiofrequency and another indication such as hepatic metastasis. Eight patients had already received treatment for their HCC: five underwent surgical resection, followed by radiochemotherapy (docetaxel/45 Gy) for a metastatic lymph node of the hepatic pedicle in one patient; one patient was treated with sorafenib at the time of his first RFA session; a chemoembolization had been carried out on one patient; and an intra-arterial hepatic injection of ${ }^{131}$ I-labeled iodized oil in another patient.

\section{Radiofrequency ablation Principles of RFA}

The rational of RFA is based on the induction of coagulation necrosis in tissues secondary to hyperthermia. It requires a generator producing a high frequency alternative sinusoidal current between 300 and $500 \mathrm{kHz}$ in order to obtain a temperature exceeding $60^{\circ} \mathrm{C}$, which leads to instantaneous and irreversible cell death. On the other side, the temperature must not rise above $100^{\circ} \mathrm{C}$ because of the increase of electric resistance by tissue ebullition and carbonization, which reduces the current diffusion, and consequently, the diameter of the treated zone. It is important to know that healthy tissue has better resistance than tumors, and thus will be preserved during the procedure. The destruction zone is progressively replaced by fibrosis. The RFA current is delivered by an electrode implanted in the tumor under ultrasound supervision. Two techniques of RFA exist: monopolar and bipolar. The monopolar mode is the most commonly employed: two electrodes are supplied by the generator, one 'active' implanted inside the tumoral lesion and the second 'passive', corresponding to a dispersion patch put on the patient's skin. Recently, a multipolar mode that permits the implantation of bipolar electrode pairs with sequential two-at-two activation was devised; in this case, all the power delivered by the generator is released directly into the tumor.

\section{RFA device and protocol}

In this study, two modes of RFA are used: Celon bipolar electrodes (Olympus) and LeVeen CoAccess monopolar deployable electrodes (Boston Scientific) or Cool-tip (Valleylab). An ethanol injection was performed in three patients, on a different nodule than the one treated with RFA. These nodules were smaller than $20 \mathrm{~mm}$. Informed consent was obtained from all patients before RFA treatment. Liver echography and injected CT scan or magnetic resonance imaging (MRI) were performed before all procedures. A chest CT scan verified the absence of thoracic metastasis. The RFA session was carried out under general anesthetic with propofol, with the patient intubated. All patients were hospitalized after the procedure, with a short duration stay. An abdominal injected CT scan or MRI was performed 4-8 weeks after the RFA in order to assess the therapeutic response. If the result was successful, the follow-up included abdominal CT scan every 3-6 months; if there was a persistent $\mathrm{HCC}$ or a recurrence during the observation, a new session was programmed according to the patient's general state of health. A chest CT scan was performed in case of recurrence or when the alpha-fetoprotein level increased. The efficiency of the procedure was defined in our study as complete necrosis of the HCC nodule, as evidenced by a loss of contrast enhancement on imaging. A local recurrence was defined by resurgence of a contrast enhancement zone in or touching a necrotic nodule.

\section{Statistical analysis}

Statistics were performed using R2 14.0 software with a significance level of $P=0.05$. The quantitative variables were analyzed with Student's $t$-tests or Mann-Whitney tests, whereas qualitative variables were studied with chi-square or Fisher's exact tests when the application conditions were not satisfied. Survival curves were compared with the help of the log-rank test.

\section{Results}

\section{Effectiveness of treatment and recurrence}

All included patients had at least one RFA session. After the first RFA session, 33 patients obtained complete necrosis of their nodule(s). The overall efficiency rate after the first 
session was $75 \%(n=33 / 44)$. According to the nodule's size, the rate increased to $94 \%(n=17 / 18)$ when nodules were smaller than $30 \mathrm{~mm}$ versus $73 \%(\mathrm{n}=19 / 26)$ when nodules were $\geq 30 \mathrm{~mm}$. Eleven patients $(25 \%)$ presented an incomplete response with a persistent enhancing area on the dynamic CT scan; these patients underwent another one or more RFA session(s). Finally, complete necrosis was obtained in 42 of 44 patients, with a mean number of 1.2 sessions per patient. During follow-up, local recurrence affected 19 of 57 successfully treated nodules $(33.3 \%)$, with a median period of 8 months (range 4-25 months). Local recurrence was defined by the reemergence of an enhancing area in contact with a previously successfully treated lesion. Six of the patients had a second RFA session, with four complete responses. A distant hepatic or extra-hepatic recurrence affected 29 of 44 patients $(66 \%)$ with a median period of 8 months (range 4-24 months). These patients were treated by chemoembolization in 12 cases (41\%) and sorafenib in ten cases $(34.5 \%)$. One patient underwent radioembolization (3\%). Six patients underwent surgery $(20.7 \%)$, including two liver transplants carried out 12 and 13 months after the first RFA session.

\section{Survival}

The recurrence-free survival at 1 year was $29.1 \%(n=7 / 24)$. Six-month and 1-year overall survival were 92.8\% $(n=39 / 42)$ and $79.4 \%(n=27 / 34)$, respectively. Metastatic progression was the cause of death for three patients, one presented fatal cirrhotic decompensation, and another passed away due to alcoholic acute hepatitis. The cause of death was not known for one patient.

\section{Complications}

Five patients presented complications after the first RFA session, meaning an overall complication rate of $10.9 \%$.

\section{Major complications}

One death occurred 48 hours after the RFA due to a hemorrhagic shock related to a massive hemoperitoneum.

\section{Minor complications}

The following minor complications occurred: a small parietal hematoma, a transitory macroscopic hematuria without renal failure, and two patients with abdominal pain for over 24 hours (one of them with low fever and inflammatory signs on blood test). No complication was seen on echography for the two patients with abdominal pain. The fever was treated by antibiotics.

\section{Subgroup analysis \\ RFA mode}

Subgroup analysis according to the RFA mode (monopolar, $\mathrm{n}=17$; bipolar, $\mathrm{n}=29$, Table 1 ) revealed a better necrotic rate in the bipolar group, which was nearly statistically significant ( $92.8 \%$ vs $81.25 \%, \mathrm{n}=26 / 28$ vs $13 / 16, P=0.06)$, with a slightly lower recurrence rate $(35.7 \%$ vs $37.5 \%, n=10 / 28$ vs $6 / 16)$; however, six of the ten $(60 \%)$ patients among the bipolar group were treated with RFA again, with four complete responses $(66.7 \%)$. In terms of complications, they also occurred less often in the bipolar subgroup (6.9\% versus $17.6 \%, n=2 / 29$ vs $3 / 17, P=0.34)$. Overall survival was better in the bipolar group than the monopolar group at 6 months $(95.8 \%$ vs $83.3 \%$, $n=23 / 24$ vs $13 / 15)$, but was not different at 1 year $(83.3 \%$, $\mathrm{n}=15 / 18$ vs $10 / 12$ ). The recurrence-free survival at 1 year was better in the bipolar group (30.7\% vs $27.2 \%, n=4 / 13$ vs $3 / 11$ ) than in the monopolar group. However, it should be noted that all results concerning survival were not statistically significant $(P=0.146$ for overall survival and $P=0.522$ for recurrence-free survival).

\section{Cirrhosis etiology}

In this subgroup analysis (Table 2), we excluded the four patients who had both etiologies. Results according to viral $(n=15)$ or alcoholic $(n=17)$ etiology showed a statistically significantly higher survival rate in the viral group: 93.3\% versus $62.5 \%(n=14 / 15$ vs $10 / 17, P=0.041$, Figure 1$)$, despite a better necrosis rate after RFA $(88.2 \%$ vs $78.6 \%, n=15 / 17$ vs $11 / 14$, $P=0.636$ ), a younger population (67 vs 76 years old, $P=0.23$ ),

Table I Subgroups according to radiofrequency mode

\begin{tabular}{|c|c|c|c|}
\hline Variables & $\begin{array}{l}\text { Monopolar } \\
\mathrm{n}=17\end{array}$ & $\begin{array}{l}\text { Multipolar } \\
\mathrm{n}=29\end{array}$ & $P$-value \\
\hline \multicolumn{4}{|l|}{ Sex, n (\%) } \\
\hline Male & $16(73.3)$ & $25(86.2)$ & 0.637 \\
\hline Female & I (26.7) & $4(13.8)$ & \\
\hline Age, years (median) & 67 & 73 & 0.161 \\
\hline \multicolumn{4}{|l|}{ Etiology of cirrhosis } \\
\hline Alcoholic & 7 & 10 & 0.650 \\
\hline Viral & 9 & 9 & 0.142 \\
\hline Other & I & 10 & 0.090 \\
\hline \multicolumn{4}{|l|}{ Child-Pugh, n (\%) } \\
\hline A & I3/17 (76.5) & $19 / 20(95)$ & 0.159 \\
\hline B & $4 / 17(23.5)$ & $\mathrm{I} / 20(5)$ & \\
\hline \multicolumn{4}{|l|}{ AFP (\%) } \\
\hline$\leq 10 \mathrm{ng} / \mathrm{mL}$ & $6 / 14(42.8)$ & $8 / 19(42.1)$ & 0.901 \\
\hline$>10 \mathrm{ng} / \mathrm{mL}$ & $8 / 14(57.2)$ & $11 / 19(57.9)$ & \\
\hline Number of nodules (average) & 1.2 & 1.5 & 0.308 \\
\hline Maximal size (median, mm) & 29 & 32 & 0.197 \\
\hline Follow-up (months, median) & 13 & 14 & 0.837 \\
\hline
\end{tabular}

Abbreviation: AFP, alpha-fetoprotein. 
Table 2 Subgroups according to cirrhosis etiology

\begin{tabular}{|c|c|c|c|}
\hline Variables & $\begin{array}{l}\text { Viral } \\
n=15\end{array}$ & $\begin{array}{l}\text { Alcoholic } \\
n=17\end{array}$ & $P$-value \\
\hline \multicolumn{4}{|l|}{ Sex, n (\%) } \\
\hline Male & II (73.3) & $17(100)$ & 0.038 \\
\hline Female & $4(26.7)$ & $0(0)$ & \\
\hline Age, years (median) & 76 & 67 & 0.230 \\
\hline \multicolumn{4}{|l|}{ Child-Pugh, n (\%) } \\
\hline$A$ & 13/14 (93) & II/I4 (79) & 0.336 \\
\hline B & $\mathrm{I} / \mathrm{I} 4(7)$ & $3 / 14(21)$ & \\
\hline \multicolumn{4}{|l|}{ AFP \% } \\
\hline$\leq 10 \mathrm{ng} / \mathrm{mL}$ & $9 / 15(60)$ & $6 / 14(42.9)$ & 0.356 \\
\hline$>10 \mathrm{ng} / \mathrm{mL}$ & $6 / 15(40)$ & $8 / 14(57.1)$ & \\
\hline Number of nodules (median) & 1 & 2 & 0.022 \\
\hline Maximal size (mm, median) & 30 & 30 & 0.911 \\
\hline Follow-up (months, median) & 15 & 11 & 0.049 \\
\hline
\end{tabular}

Abbreviation: AFP, alpha-fetoprotein.

and a shorter follow-up in the alcoholic group (11 vs 15 months, $P=0.049$ ). However, local recurrence was more prevalent in the alcoholic group $(53.3 \%$ vs $36.4 \%, n=8 / 15$ vs $n=4 / 11, P=0.391)$ which contains patients with more serious symptoms, as shown by a higher percentage at Child-Pugh stage B $(21.4 \%$ vs $7.1 \%$, $\mathrm{n}=3 / 14$ vs $1 / 14, P=0.336$ ) and a higher number of nodules more important ( 2 vs $1, P=0.022$ ). Otherwise, as expected, we found a higher tendency to distant recurrences in the viral group ( $71.4 \%$ vs $50 \%, \mathrm{n}=10 / 14$ vs $8 / 16, P=0.232)$.

\section{Discussion}

The therapeutic strategy for $\mathrm{HCC}$ is based on Barcelona Clinic Liver Cancer staging, ${ }^{3}$ including ablation techniques such as RFA in very early and early stages when the Milan criteria are met (less than three nodules $<3 \mathrm{~cm}$ ) and when liver transplantation or surgical resection are contraindicated.

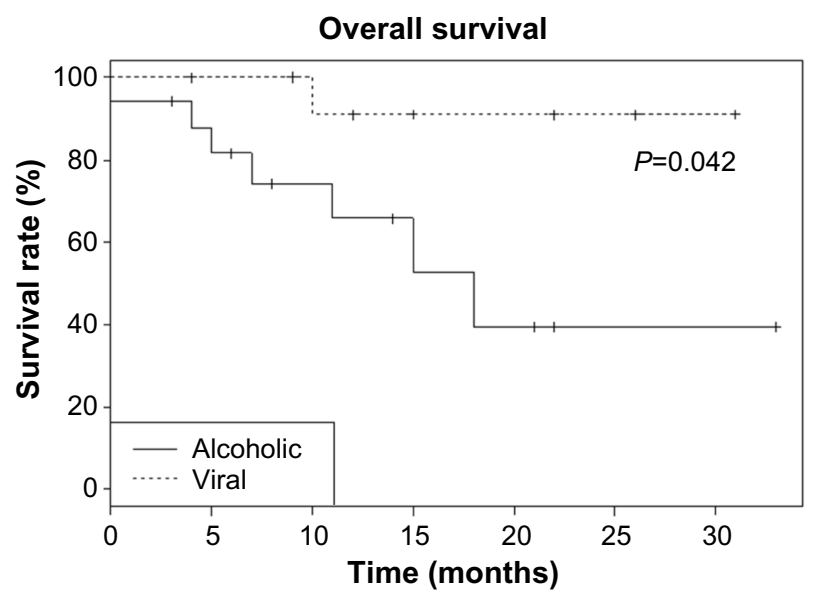

Figure I Overall survival curve according to alcoholic or viral etiology of the cirrhosis.
Many studies have evaluated RFA for HCC treatment. ${ }^{4-9}$ These studies have concluded that RFA is a minimal invasive technique resulting in excellent local tumor control and longterm survival gain, with acceptable morbidity. Local control of the disease is the first purpose of the treatment. Several poor prognostic factors were highlighted in the literature: a bulky tumor, infiltrating or undifferentiated, and its localization near hepatic vessels. The size of the tumor is the main prognostic factor, ${ }^{10-15}$ with rates of complete necrosis of $80 \%-100 \%$ for small tumors $<3 \mathrm{~cm}, 50 \%-80 \%$ for $3-5 \mathrm{~cm}$ lesions, and $25 \%$ for nodules $>5 \mathrm{~cm} .{ }^{10}$ In our study, after the first session, $75 \%$ of the nodules were completely necrotic, and the success rate was dependent on the size of the nodules: $94 \%$ for tumors $<30 \mathrm{~mm}$ versus $73 \%$ for tumors $\geq 30 \mathrm{~mm}$. The final rate of local response was $95.4 \%$, after a mean number of 1.2 RFA sessions per patient.

Regarding complications of radiofrequency, Mulier et al ${ }^{16}$ conducted a meta-analysis of 82 studies involving 3,670 patients, which revealed a mortality rate of $0.5 \%$ and an overall complication rate of $8.9 \%$. Forty-three Japanese centers ${ }^{17}$ identified comparable rates (mortality $0.3 \%$, morbidity $8 \%$ ). These values were higher in our series, with an overall complication rate of $10.9 \%$ and mortality rate of $2.2 \%$ (1/46 patients), most probably due to its small size. We can conclude that although RFA is considered to be a safe technique, it is not a risk-free technique and should be performed by experienced operators.

In our study, RFA was performed under general anesthesia because it is a long and painful procedure for the patient, especially when there is more than one nodule $(30 \%$ of our population), and when nodule's location is subcapsular. With intubation, the breathing of the patient can be temporarily blocked, which helps the insertion of the electrode, especially when the nodule is located in the hepatic dome, and thus only accessible during forced inspiration. Moreover, a recent retrospective analysis suggested that treatment of small HCCs by RFA under general anesthesia is associated with a reduced risk of cancer recurrence relative to locoregional anesthesia, with no effect of anesthetic technique on overall survival detected. ${ }^{18}$ However, prospective, randomized trials are needed to confirm these results.

Some long-term clinical trials have shown that RFA results in a long-term survival gain for patients with HCC. Since 2005, eight cohorts with large series of patients evaluating RFA showed survival rates at 5 years from $41 \%$ to $64 \%$ depending on the tumor size (Table 3 ). Overall survival at 1 year, estimated at $79.4 \%$ in our study, is comparable to the literature data: $76 \%-97 \%$. A study by $\mathrm{Hu}$ et $\mathrm{al}^{19}$ found a 
Table 3 Comparison with others' studies

\begin{tabular}{|c|c|c|c|c|c|c|c|c|}
\hline $\begin{array}{l}\text { First } \\
\text { author }\end{array}$ & Year & $\mathbf{N}$ & $\begin{array}{l}\text { Tumor size } \\
\max (\mathrm{cm})\end{array}$ & $\begin{array}{l}\text { Mean follow-up } \\
\text { (months) }\end{array}$ & $\begin{array}{l}\text { Major } \\
\text { complications }\end{array}$ & $\begin{array}{l}\text { Local } \\
\text { recurrence }\end{array}$ & $\begin{array}{l}\text { Distant } \\
\text { recurrence }\end{array}$ & $\begin{array}{l}\text { Overall } \\
\text { survival }\end{array}$ \\
\hline \multirow[t]{3}{*}{ Tateishi ${ }^{5}$} & 2005 & 319 & $<5$ & 28 & $4 \%$ & $8.7 \%$ & $60 \%$ & $95 \%$ at I year \\
\hline & & & & & & & & $78 \%$ at 3 years \\
\hline & & & & & & & & $54 \%$ at 5 years \\
\hline \multirow[t]{3}{*}{ Lencioni $^{4}$} & 2005 & 206 & $<5$ & 24 & $2 \%$ & $10 \%$ & $40 \%$ & $97 \%$ at I year \\
\hline & & & & & & & & $67 \%$ at 3 years \\
\hline & & & & & & & & $41 \%$ at 5 years \\
\hline \multirow[t]{3}{*}{ Chen $^{6}$} & 2005 & 256 & $<8$ & 24 & $2.4 \%$ & $\mathrm{~N} / \mathrm{A}$ & N/A & $83 \%$ at I year \\
\hline & & & & & & & & $67 \%$ at 3 years \\
\hline & & & & & & & & $41 \%$ at 5 years \\
\hline \multirow[t]{3}{*}{$\mathrm{Choi}^{7}$} & 2007 & 570 & $<5$ & 30 & $1.9 \%$ & $11.8 \%$ & $52 \%$ & $95 \%$ at I year \\
\hline & & & & & & & & $70 \%$ at 3 years \\
\hline & & & & & & & & $58 \%$ at 5 years \\
\hline \multirow[t]{2}{*}{ Livraghi ${ }^{8}$} & 2008 & 216 & $<2$ & 31 & $1.8 \%$ & $0.9 \%$ & N/A & $76 \%$ at I year \\
\hline & & & & & & & & $55 \%$ at 5 years \\
\hline \multirow[t]{2}{*}{ N'Kontchou' } & 2009 & 235 & $<5$ & 27 & $0.9 \%$ & $11.5 \%$ & $42 \%$ & $60 \%$ at 3 years \\
\hline & & & & & & & & $40 \%$ at 5 years \\
\hline \multirow[t]{2}{*}{ Francica $^{35}$} & 2013 & 365 & $<3$ & 37 & $2.2 \%$ & $22 \%$ & $\mathrm{~N} / \mathrm{A}$ & $80 \%$ at 3 years \\
\hline & & & & & & & & $64 \%$ at 5 years \\
\hline \multirow[t]{3}{*}{$\mathrm{Kim}^{38}$} & 2013 & 1,305 & $<5$ & 33.4 & $2 \%$ & $19.4 \%$ & $54.8 \%$ & $95.5 \%$ at I year \\
\hline & & & & & & & & $77.9 \%$ at 3 years \\
\hline & & & & & & & & $59.7 \%$ at 5 years \\
\hline Our series & 2012 & 46 & $<6$ & 15.3 & $2.2 \%$ & $33.3 \%$ & $66 \%$ & $79.4 \%$ at I year \\
\hline
\end{tabular}

Abbreviation: N/A, not available.

lower survival rate of $55.1 \%$; however, their median tumor size was larger $(6.1 \mathrm{~cm})$. In our subgroup analysis comparing survival according to the etiology of cirrhosis, our results were inconsistent with those published by Giovannini et al in $2003,{ }^{20}$ which found a better prognosis for radiofrequency treatment in patients with alcoholic cirrhosis: 2-year survival was statistically significantly different $(57.7 \%$ vs $77.7 \%)$ for the alcoholic group. Nevertheless, our alcoholic group was constituted by patients who have more serious symptoms, with a higher Child-Pugh score and a higher number of lesions.

It is classically considered that RFA is reserved for cirrhotic patients not eligible for surgical resection. In Europe and US, this concerns patients with portal hypertension and high rate of bilirubin. Therefore, only $5 \%-10 \%$ of the patients are eligible for surgery. The main drawback of RFA and surgery is that the cirrhotic liver is left in place, retaining the risk of tumor recurrence and other complications of cirrhosis. The rate of intrahepatic recurrence after resection is $70 \%$ at 5 years, combining true recurrence, which usually occurs within 2 years and the development of de novo tumors. ${ }^{23}$ Microvascular invasion, poorly differentiated character and multifocal disease are predictive factors of early recurrence. ${ }^{23,24}$ The rate of intrahepatic recurrence after radiofrequency is comparable to that in those post-resection. In the studies by Izumi et a ${ }^{25}$ and Shiina et al, ${ }^{13}$ the number of tumors and hepatitis $\mathrm{C}$ viral infection were associated with recurrence, in agreement with the literature, which highlights an annual incidence for $\mathrm{HCC}$ of $2 \%$ for alcoholic cirrhosis versus $3 \%-8 \%$ for hepatitis $\mathrm{C}$ viral cirrhosis. ${ }^{26,27}$

In fact, several retrospective studies and randomized trials have compared radiofrequency and surgical resection: ${ }^{28-33}$ for comparable groups of patients, none found superiority of resection in terms of intrahepatic recurrence and survival. Moreover, RFA is easily repeatable in case of recurrence and less invasive, even if it does not provide a pathological analysis. Therefore, local recurrence remains the principal issue, which is nonexistent after surgical resection. On this point, a recent histological study on explants after multipolar radiofrequency confirmed the complete destruction of all HCC nodules $<4 \mathrm{~cm} .{ }^{34}$ In our study, we found a higher sterilization rate for the bipolar mode compared to the monopolar mode; however, we obtained similar rates for local recurrence in the two groups, at around 36\%. Nevertheless, $60 \%$ of these patients were re-treated, with $66.7 \%$ achieving complete response. The recurrence-free survival at 1 year was better in the bipolar group. But the use of the multipolar mode has a steep learning curve in order to obtain the same results as Seror et al. ${ }^{34}$ Therefore, for small tumors ( $\leq 3 \mathrm{~cm}$ for monopolar and $\leq 5 \mathrm{~cm}$ for multipolar), there is a rationale today to first try RFA, including in operable patients. Multipolar radiofrequency could even compete 
against surgery as standard treatment for small nodules and this may be confirmed by future studies randomizing surgery and RFA. However, for HCC in healthy livers, resection remains the treatment of choice.

The most recent large studies (Table 3) show a local recurrence rate between $0.9 \%$ and $22 \%$ and a distant recurrence rate between $42 \%$ and $60 \%$. Our result in terms of the distant recurrence rate was slightly higher $(66 \%)$, with a median of 8 months. Nevertheless, a difference was observed between the local recurrence rates in the literature and those obtained in our study (33.3\%). Several hypotheses were suspected to explain this difference. We used as criteria of local recurrence nodules appearing in contact of radiofrequency area. When we only consider the reappearance of contrast enhancement on the treated area, the local recurrence rate drops to $23 \%$, which is close to the $22 \%$ found by Francica et al in $2013 .{ }^{35}$ Moreover, the definition of local recurrence in the literature is not clear: it is defined by the Society of Interventional Radiology Technology Assessment Committee and the International Working Group on Image-Guided Tumor Ablation by "the presence of a larger area than the original tumor area on the scanner". ${ }^{36}$ The rapid evolution of imaging has permitted improvement of the scanning accuracy for early detection of recurrence; this is also a hypothesis that could explain the discrepancy with the studies before 2009. Recently, in a study testing CT fusion imaging of pre- and post-RFA CT scans, some HCCs were assessed as incomplete ablation on the CT fusion images, although they were considered to be completely ablated on side-by-side images at the time of treatment; incomplete ablation was revealed to be the only independent risk factor for local tumor progression. ${ }^{37}$ In terms of limitations, the small size of our study induces a lack of statistical power. Additionally, the fact that $30 \%$ of our cases were multi-focal and that the average tumor size was $>3 \mathrm{~cm}$ may explain the higher rates of recurrence.

\section{Conclusion}

Treatment of HCC has changed dramatically in the last decade and has become a priority for research due to the increase in the number of cases worldwide. RFA has earned its place in the therapeutic strategy thanks to the many studies proving its effectiveness, especially for small tumors, where its benefit seems equivalent to surgical resection. Multipolar RFA is likely a more efficient treatment with fewer complications. Nevertheless, this technique has a steep learning curve in order to achieve the results obtained by Seror et al. ${ }^{34}$ Our study confirms the effectiveness of RFA, despite a small population with a short median follow-up, but also highlights the problem of local and distant recurrence on a diseased liver.

In conclusion, RFA technology has evolved, especially with the advent of the multipolar mode, which allows the treatment of lesions with a better local response as well as the 'no-touch ablation' technique, which is the basic principle of oncology surgery. These changes serve to broaden the scope of this technique.

\section{Disclosure}

The authors report no conflicts of interest in this work.

\section{References}

1. Llovet J, Burroughs A, Bruix J. Hepatocellular carcinoma. Lancet. 2003;362(9399):1907-1917.

2. Gervais DA, Arellano RS. Percutaneous tumor ablation for hepatocellular carcinoma. AJR Am J Roentgenol. 2011;197(4):789-794.

3. Llovet JM, Brú C, Bruix J. Prognosis of hepatocellular carcinoma: the BCLC staging classification. Semin Liver Dis. 1999;19(3):329-338.

4. Lencioni R, Cioni D, Crocetti L, et al. Early-stage hepatocellular carcinoma in patients with cirrhosis: long-term results of percutaneous image-guided radiofrequency ablation. Radiology. 2005;234(3): 961-967.

5. Tateishi S, Shiina S, Teratani T, et al. Percutaneous radiofrequency ablation for hepatocellular carcinoma. An analysis of 1000 cases. Cancer. 2005;103(6):1201-1209.

6. Chen MH, Yan K, Yang W, et al. [Long-term (5 years) outcome of radiofrequency ablation for hepatocellular carcinoma in 256 cases]. Beijing Da Xue Xue Bao. 2005;37(6):671-672. Chinese.

7. Choi D, Lim H, Rhim H, et al. Percutaneous radiofrequency ablation for early-stage hepatocellular carcinoma as a first-line treatment: long-term results and prognostic factors in a large single-institution series. Eur Radiol. 2007;17(3):684-692.

8. Livraghi T, Meloni F, Di Stasi M, et al. Sustained complete response and complications rates after radiofrequency ablation of very early hepatocellular carcinoma in cirrhosis: is resection still the treatment of choice ? Hepatology. 2008;47(1):82-89.

9. N'Kontchou G, Mahamoudi A, Aout M, et al. Radiofrequency ablation of hepatocellular carcinoma: long-term results and prognostic factors in 235 Western patients with cirrhosis. Hepatology. 2009;50(5):1475-1483.

10. Livraghi T, Goldberg S, Lazzaroni S, et al. Hepatocellular carcinoma: radio-frequency ablation of medium and large lesions. Radiology. 2000;214(3):761-768.

11. Lencioni R, Allgaier H, Cioni D, et al. Small hepatocellular carcinoma in cirrhosis: randomized comparison of radio-frequency thermal ablation versus percutaneous ethanol injection. Radiology. 2003;228(1):235-240.

12. Lin SM, Lin CJ, Lin CC, Hsu CW, Chen YC. Radiofrequency ablation improves prognosis compared with ethanol injection for hepatocellular carcinoma $<$ or $=4 \mathrm{~cm}$. Gastroenterology. 2004;127(6):1714-1723.

13. Shiina $\mathrm{S}$, Teratani $\mathrm{T}$, Obi $\mathrm{S}$, et al. A randomized controlled trial of radiofrequency ablation with ethanol injection for small hepatocellular carcinoma. Gastroenterology. 2005;129(1):122-130.

14. Lin SM, Lin CJ, Lin CC, Hsu CW, Chen YC. Randomised controlled trial comparing percutaneous radiofrequency thermal ablation, percutaneous ethanol injection, and percutaneous acetic acid injection to treat hepatocellular carcinoma of $3 \mathrm{~cm}$ or less. Gut. 2005;54(8):1151-1156. 
15. Livraghi T, Goldberg S, Lazzaroni S, Meloni F, Solbiati L, Gazelle G. Small hepatocellular carcinoma: treatment with radio-frequency ablation versus ethanol injection. Radiology. 1999;210(3):655-661.

16. Mulier S, Mulier P, NiY, et al. Complications of radiofrequency coagulation of liver tumours. Br J Surg. 2002;89(10):1206-1222.

17. Kasugai H, Osaki Y, Oka H, Kudo M, Seki T. Severe complications of radiofrequency ablation therapy for hepatocellular carcinoma: analysis of 3,891 ablations in 2,614 patients. Oncology. 2007;72 Suppl 1: $72-75$.

18. Lai R, Peng Z, Chen D, et al. The effects of anesthetic technique on cancer recurrence in percutaneous radiofrequency ablation of small hepatocellular carcinoma. Anesth Analg. 2012;114(2):290-296.

19. Hu D, Ren Y, Wang C. [Percutaneous radiofrequency ablation treatment of hepatocellular cancer]. Zhonghua Yi Xue Za Zhi. 2001;81(17) 1046-1049. Chinese.

20. Giovannini M, Moutardier V, Danisi C, Bories E, Pesenti C, Delpéro JR. Treatment of hepatocellular carcinoma using percutaneous radiofrequency thermoablation: results and outcomes in 56 patients. $J$ Gastrointest Surg. 2003;7(6):791-796.

21. Barbare JC, Boige V, Boudjema K, Lecesne R, Trinchet JC. Hepatocellular carcinoma (primary cancer of the liver). Gastroenterol Clin Biol. 2006;30 Spec No 2:2S57-2S61.

22. Bruix J, Sherman M; American Association for the Study of Liver Diseases. Management of hepatocellular carcinoma: an update. Hepatology. 2011;53(3):1020-1022.

23. Llovet J, Schwartz M, Mazzaferro V. Resection and liver transplantation for hepatocellular carcinoma. Semin Liver Dis. 2005;25(2):181-200.

24. Imamura $\mathrm{H}$, Matsuyama $Y$, Tanaka E, et al. Risk factors contributing to early and late phase intrahepatic recurrence of hepatocellular carcinoma after hepatectomy. J Hepatol. 2003;38(2):200-207.

25. Izumi $\mathrm{N}$, Asahina $Y$, Noguchi $\mathrm{O}$, et al. Risk factors for distant recurrence of hepatocellular carcinoma in the liver after complete coagulation by microwave or radiofrequency ablation. Cancer. 2001;91(5):949-956.

26. Cottone M, Turri M, Caltagirone M, et al. Screening for hepatocellular carcinoma in patients with Child's A cirrhosis: an 8-year prospective study by ultrasound and alphafetoprotein. J Hepatol. 1994;21(6): 1029-1034.

27. Mori M, Hara M, Wada I, et al. Prospective study of hepatitis B and $\mathrm{C}$ viral infections, cigarette smoking, alcohol consumption and other factors associated with hepatocellular carcinoma risk in Japan. Am J Epidemiol. 2000;151(2):131-139.
28. Lu M, Kuang M, Liang L, et al. [Surgical resection versus percutaneous thermal ablation for early-stage hepatocellular carcinoma: a randomized clinical trial]. Zhonghua Yi Xue Za Zhi. 2006;86(12):801-805. Chinese.

29. Chen MS, Li JQ, Zheng Y, et al. A prospective randomized trial comparing percutaneous local ablative therapy and partial hepatectomy for small hepatocellular carcinoma. Ann Surg. 2006;243(3):321-328.

30. Llovet JM, Bruix J. Novel advancements in the management of hepatocellular carcinoma in 2008. J Hepatol. 2008;48 Suppl 1:S20-S37.

31. Petrowsky H, Busuttil RW. Resection or ablation of small hepatocellular carcinoma: what is the better treatment? J Hepatol. 2008;49(4): 502-504.

32. Peng ZW, Lin XJ, Zhang YJ, et al. Radiofrequency ablation versus hepatic resection for the treatment of hepatocellular carcinoma $2 \mathrm{~cm}$ or smaller: a retrospective comparative study. Radiology. 2012;262(3): 1022-1033.

33. Tohme S, Geller DA, Cardinal JS, et al. Radiofrequency ablation compared to resection in early-stage hepatocellular carcinoma. HBP (Oxford). 2013;15(3):210-217.

34. Seror O, N'Kontchou G, Ibraheem M, et al. Large (>or-5.0-cm) HCCs: multipolar RF ablation with three internally cooled bipolar electrodes initial experience in 26 patients. Radiology. 2008;248(1):288-296.

35. Francica G, Saviano A, De Sio I, et al. Long-term effectiveness of radiofrequency ablation for solitary small hepatocellular carcinoma: a retrospective analysis of 363 patients. Dig Liver Dis. 2013;45(4): 336-341.

36. Goldberg SN, Grassi CJ, Cardella JF, et al; Society of Interventional Radiology Technology Assessment Committee. Image-guided tumor ablation: standardization of terminology and reporting criteria. $J$ Vasc Interv Radiol. 2005;16(6):765-778.

37. Makino Y, Imai Y, Igura T, et al. Utility of computed tomography fusion imaging for the evaluation of the ablative margin of radiofrequency ablation for hepatocellular carcinoma and the correlation to local tumor progression. Hepatol Res. 2013;43(9):250-258.

38. Kim Y, Lim H, Rhim H, et al. Ten-year outcomes of percutaneous radiofrequency ablation as first-line therapy of early hepatocellular carcinoma: analysis of prognostic factors. J Hepatol. 2013;58(1):89-97.
Hepatic Medicine: Evidence and Research

\section{Publish your work in this journal}

Hepatic Medicine: Evidence and Research is an international, peerreviewed, open access journal covering all aspects of adult and pediatric hepatology in the clinic and laboratory including the following topics: Pathology, pathophysiology of hepatic disease; Investigation and treatment of hepatic disease; Pharmacology of drugs used for

\section{Dovepress}

the treatment of hepatic disease. Issues of patient safety and quality of care will also be considered. The manuscript management system is completely online and includes a very quick and fair peer-review system, which is all easy to use. Visit http://www.dovepress.com/ testimonials.php to read real quotes from published authors. 